\title{
Relationship between Employee Compensation and Productivity a Case Study of Benin Owena River Basin Development Authority
}

\author{
Adedeji Adebola Daramola \\ Acting Managing Director \\ Owena Energy Limited \\ Ondo State, Nigeria \\ Email: adeboladd@gmail.com
}

\begin{abstract}
The attitude of employees about a particular work will affect the overall performance of an organization. Also, the performance of an organization is a goodwill asset to the organization. The study aimed at examining the relationship between employee compensation and productivity among workers of Benin Owena River Basin Development Authority. In order to achieve this, questionnaire was designed. The completed questionnaires were processed and analyzed using Chi-Square. The findings of this study revealed that there is a relationship between employee compensation and productivity. Hence, there is need to motivate workers at all levels in order to increase organization's productivity.
\end{abstract}

Keywords: Employee Compensation, Workers productivity, RORBDA

\section{Introduction}

\section{I.IBackground to Study}

Motivation can be defined as the set of factors that cause people to behave in certain ways (Schwartz, 2006). Motivation is derived from the term motive which is a reason for doing something (Amstrong, 2008), the reason can either be internal (intrinsic) or external (extrinsic) factors (Herzberg et al., 1957). Motivation can be described as goal-oriented behavior (Amstrong, 2008). Drafke (2002) defines motivation as simply an incentive to act. Motivation is among the key concerns of organizations in the modern business environment, as it has been identified to be critical in achieving business goals and objectives. This means giving close attention to how individuals can best be motivated to achieve objectives set for them (Amstrong, 2008).

Key factors that determine employee motivation are satisfaction, recognition, appreciation, inspiration and compensation (Bowen, 2000). Organizations that recognize the importance of motivating employees often implement strategies that consistently motivate their employees to achieve the organizations objectives. Such strategies for improving motivation include compensation, employee participation, feedback and work environment which ensure that employees' needs and requirements are met (Bowen, 2000). Clegg and Birch (2002) argues that the thought of incentive is in itself motivational, in fact most motivation comes from anticipation than the delivery of the incentive itself.

Compensation is one of the key drivers of motivation because humans are naturally inclined to perform better when they perceive that they will get sufficient payment or returns from their efforts. While people exert effort for different reasons, today's competitive economic environment coupled with the consumer society has made compensation arguably the most important motivation factor. Most people are motivated by money at least for their basic needs and wants. Compensation in any form is the most obvious extrinsic reward; it provides the carrot that most people want (Amstrong, 2008). DeNisi and Griffins (2008) defines compensation as the set of rewards that organizations provide to individuals in return for their willingness to perform various jobs and tasks within the organization.

Certain problems of inadequate motivation however do arise as it concerns certain individuals who come into the work situation with differences in expectation, behavior and outlook. These problems of individual motivation inadequately may be divided into two categories. Firstly, the inability of certain individuals to be motivated may stem from the fact that there is a deficiency in their personality. For such people, the desire to avoid failure may be too strong while paradoxically, the motive to produce positive results may be too weak. This could produce a general resistance to achievement-oriented activity that should naturally be overcome by other extrinsic modes of motivation if there is to be any spur to achievement oriented activity at all. Secondly, even when the achievement motive is relatively strong, the challenges before the individual worker may be proven to be inadequate or too difficult, whichever of these that apply to the individual worker will usually manifest themselves in different ways such as lack of enthusiasm or premature surrender (Bryans and Crouin, 2005). 
In spite of all these apparent attendant problems of motivation, and productivity, every organisation do necessarily seek means of ensuring continuous productivity, which would be geared towards the accomplishment of organisation goals. The organizational system under study cannot be said to be different in any way, in terms of producing the result for which it was set up. In all these processes the public organisation and indeed the Benin Owena River Basin Development Authority (BORBDA) has significant impact in Ondo State. The study will justify the relationship between higher employee compensation and higher productivity.

\section{Literature Review}

\section{I Empirical Evidence on Employee Motivation}

The fields of employee motivation and employee performance are solidly grounded in the researcher of Maslow, Taylor, and Herzberg, to name just a few. The concepts of motivation and performance are constructs within the larger organizational behavior model. While each of these constructs can be reviewed on their own, employee motivation is linked closely to employee performance. By conducting the search in this manner the resultant articles were specific case studies of employee motivation in various organizations. The resultant case studies looked at a range of topics on both employee motivation and employee performance and how these constructs can be connected.

One particular study looked specifically at "the followers" of an organization and what key factors a leader needs to know about the various types of followers. The case studies in this review expand upon the work of Maslow in brief, and Herzberg. In 'Beyond the Fringe', Simms discusses how various organizations utilize tailored versions of "non-cash rewards" as employee incentives. Simms suggests that Herzberg's view of salary as not being a motivator holds. The ability to hold up an incentive that doesn't get absorbed by the employee's monthly bills has a larger effect on employee motivation.

He also suggests it may be more acceptable to boast about a special award or party rather than an employee's salary raise. Simms then goes on to expand the discussion of non- cash rewards such as flex time, employee of the month, and tailored goal incentives. Simms argues it is important for employers to communicate these benefits to employees because many employees don't understand their total compensation package. By communicating the total package, the employer reinforces their commitment to the employees and helps to motivate the employee. This motivation leads to greater employee satisfaction and performance (Simms, 2007).

The case study of the Harrah's Entertainment sales teams lays out the use of team incentives to increase sales across the various branches of the Harrah's Entertainment family of products. However, the core to the incentive packages, that Jakobson discusses, is the use of Merchandise Awards. Jakobson states that Merchandise Awards are even more effective than Top Seller Trips. Harrah's also uses simple employee motivation tactics such as recognition at weekly and monthly sales meetings of the top sales teams (Jakobson, 2007).

Whiteling (2007) looks at the cases of Reuters and supermarket giant Sainsbury's to show how important it is to create a culture where employees become directly involved in suggestions for change. By creating a culture where employee input is valued and utilized, the changes faced by the organization are better understood and receive the support of the employees. This also has the side effect of creating employee motivation to support and accomplish the organizations goals and change efforts (Whiteling, 2007). Silverman utilizes a similar strategy to create a high-performance workforce. Silverman suggests keeping employees engaged by working with storytelling. Employers can systematically ask employee's to tell their story for good or not-so good situations. In this way, an employee/employer relationship can be forged which can help foster mutual support and idea sharing (Silverman, 2006).

Similar to Whiteling, Silverman suggests that the organizations culture needs to be developed around the concept of storytelling. Employees need to feel their stories are being heard, understood, and valued by those requesting the stories. By forging these relationships, the employee feels valued by the employer, supervisor, and organization as a contributor. This value translates into higher work performance and stake within the organization (Silverman, 2006; Whiteling, 2007). Sharbrough's (2006) study looks at the correlations between leader's use of Motivating Language (ML) and employee job satisfaction and the perception of a supervisor's effectiveness. In both cases, there was a statistically significant correlation in this study between a leader's use of ML and employee job satisfaction and the perception of a supervisor's effectiveness.

This correlation can be utilized by organizations to measure a leader's use of ML and determine levels of employee satisfaction as well as determine the perceived effectiveness of a supervisor Kellerman(2007) has expanded the work of Zaleznik, Kelley, and Chaleff to create what he calls a level of engagement to classify the followers of an organization. This employee continuum ranges from "feeling and doing absolutely nothing" to "being passionately committed and deeply involved." In this way, a leader can assess their subordinates and tailor a leadership approach to maximize the affect a particular effort will have on employee motivation.

\subsection{Effects of Motivation on Productivity}

Productivity in general has been defined in the Cambridge International and Oxford Advance Learner's dictionaries as the rate at which goods are produced with reference to number of people and amount of materials necessary to produced it. On the other 
hand, productivity has been defined as the utilization of resources in producing a product or services (Gaissey, I993). It has further been defined as the ratio of the output (good and services) and input (Labour, capital or management). The definition of productivity is utilized by economists at the industrial level to determine the economy's health, trends and growth rate whiles at the project level, it applies to areas of planning, cost estimating, accounting and cost control (Mojahed, 2005).

Several factors affect labour productivity and prominent among them is the basic education for any effective labour force. In addition to the above is the diet of the labour force and social overhead such as transportation and sanitation (Heizer and Render, 1999). Furthermore, motivation, team building, training and job security have a significant bearing on the labour productivity. Coupled with the afore-stated factors, labour productivity cannot be achieved without maintaining and enhancing the skills of labour and human resource strategies. Better utilized labour with stronger commitment and working on safe jobs also contribute to affect labour productivity (Wiredu, I989).

\subsection{Effects of Motivation on Performance}

The performance of employees will make or break a company; this is why it is important to find a variety of methods of motivating employees. "Motivation is the willingness to do something," wrote Stephen Robbins and David A. DeCenzo in their book "Supervision Today." "It is conditioned by this action's ability to satisfy some need for the individual." The most obvious form of motivation for an employee is money; however, there are other motivating factors that must be considered. Every employee within a company is different and, therefore, is motivated to perform well for different reasons.

Due to the differences within an organization, it is important for a manager to get to know her employees and understand what motivates their performance. "If you're going to be successful in motivating people, you have to begin by accepting and trying to understand individual differences," Robbins and DeCenzo report in their book "Supervision Today." Money is the most important motivator for employee performance but it is important for companies to find other ways to motivate. This involves getting to know their employees and what drives them, then making sure managers utilize appropriate motivational techniques with each employee. When appropriate motivation techniques are used, employee performance will improve.

\section{Methodology}

\section{I Population of Study}

A cross section of the staff of BORBDA comprising of 45 subjects drawn from every class and cadre of the organization was sampled. For the purpose of this study, the workers were divided into three major groups namely:

- The contract staff

- The permanent staff officers

- The management staff officers

Careful analyses of the above data revealed that the $9 \%$ are management staff, $55.5 \%$ are permanent staff, and the remaining $35.5 \%$ are contract staff. Information was gathered from the population.

\subsection{Research Instrumentation}

Questionnaire was used for collecting responses from the subject selected for the study. The questionnaire consisted of two component parts. The first part consisted of questions that make it possible for the bio-data to be collected. This part of the questionnaire was intended to elicit information about the sex, age, and working category and employment duration of the respondents. The other part of the questionnaire contained the dependent variables which were designed to elicit responses from respondents on familiarity dimension and to find out the extent to which this affects their motivation to work and increase productivity. There were fifteen questions on the whole.

\subsection{Instrument Scoring Scale}

The scale of response on the questionnaire was from strongly Agree, Agree, Undecided, Disagree to Strongly Disagree. The calibrations for the positive items were such that they were scored: $5,4,3,2$, and I. The negative structured items were scored as follows: I, 2, 3, 4, and 5. The different motivational factors were aggregate and the total for each motivational factor was found. Items on the dependent variables (work approach) were also aggregated and the total computed.

\subsection{Data Collection Procedure}

A total of 45 respondents completed and returned the questionnaires. They all filled and returned questionnaires for analytical purposes.

\subsection{Data Analysis Technique}

Two basic simple analytical tools were used in the analysis. Namely, use of simple percentage and the Chi-Square method of hypothesis testing. The chi-square is used to test hypotheses about the distribution of observations into categories. The null 
hypothesis (Ho) is that the observed frequencies are the same (except for chance variation) as the expected frequencies (Adeniran, 2018). If the frequencies you observe are different from expected frequencies, the value of $\chi 2$ goes up. If the observed and expected frequencies are exactly the same, $\chi 2=0$. You test whether a given $\chi 2$ is statistically significant by testing it against a table of chi-square distributions, according to the number of degrees of freedom for your sample, which is the number of categories minus $\mathrm{I}$. The chi-square assumes that you have at least 5 observations per category

\section{Result and Discussion \\ 4.IRelationship between Employees' Compensation and Work Productivity}

In order to examine this, relevant questions like: does well-motivated staffs have a positive attitude towards work; and does interpersonal relationship between top management and staff should be encouraged. From the analysis, it was revealed that the calculated value of $\mathrm{X}^{2}$ (I4.82) exceeds or is greater than the critical value of $\mathrm{X}^{2}(\mathbf{9 . 4 9})$, hence the null hypothesis will be rejected and accept the alternative, which would state that there is a significant relationship between motivational factors and work productivity for staff of BORBDA. This significant relationship is supported by Vroom in his work "work and motivation" (I964), he believed that there is considerable evidence that performance or productivity increases given adequate reward. This under lying belief is hinged on his expectancy theory as it is sometime called.

\section{Conclusion and Recommendation}

Compensation can be inform of money (salary) or financial incentive being a right of the worker is taken for granted and that certain other factors would be needed to adequately motivate or satisfy the workers. Such factors include job security, recognition etc. This study examined and reveals that there is a relationship between employees compensation and worker productivity. It is crucial to note that the management is not static, as it is subject to flexibilities in changing principles and heads. However, the workers in the organization will remain. It could be noted that higher compensation of workers will leads to increasing productivity in BORBDA.

\section{References}

Adeniran, A. O. (2018). Establishing Chi Square as a Non-Parametric Test in Descriptive Statistics. Science \& Technology, 4, IO6-II3.

Armstrong M. (2006). A Hand Book of Human Resource Management Practice 7th Edition. Kogan Page Limited London NI 9JN, UK.

Bryans P. and Cronin T.P. (2005). Organisation Theory, Facts on File Inc., 20005

Dhar R. and Werten B. K. (2000). Consumer Choice Between Hedonic and Utilitarian Goods, Journal of Marketing Research

Dutton G. (1998). The re-enchantment of work” AMA Management Review February I998 Ed.

Festinger L. (1958). The Motivating Effects of Cognisance Dissnance in G. Lindzey (Ed). Assessment of Human Motives, New York Holt, 1958

Heizer J. and Render B (1999). Principles of Operations Management

Herzberg F. (1959). The Motivation to Work, New York, John Wiley and Sons, 1959

Jakobson L. (2007). Harrah's Teams Up, Business Source Premier Database, January, 2007

Kellerman B. (2007). What Every Leader Needs to Know About Followers, Business Source Premier Database, January 2007

Laurie J. M. (1996). Management and Organisational Behaviour” fourth edition pitman publishers Washington DC

Maslow A. (1954). Motivation and Personality, Harper and Row New York, New York, 1954

McGregor, D. (I960). The Human Side of Enterprise, McGraw Hill Professional, I960

ORBRDA 1986 Annual Report p. I (June I987).

River Basin Development Authorities Decree (No. 87) p. A683 (1979).

Robbins, S., and David, A. D. C. (2004). Fundamentals of Management, Pearson Prentice Hall.

Sharbrough W. (2006). Motivating Language in Industry, Business Source Premier Database, January.

Szilagyi A. D. and Marc J. W., JR., (I987). Organisational Behaviour and performance 4th Ed, London Scott, Foresman and Company.

Taylor, F. W (I9I I). Principles of Science Management, Routledge.

Whiteling I. (2007). A Message from the Frontline, Business Source Premier Database.

\section{Copyrights}

Copyright for this article is retained by the author(s), with first publication rights granted to the journal. This is an open-access article distributed under the terms and conditions of the Creative Commons Attribution license (http://creativecommons.org/licenses/by/4.0/). 